\title{
Firing Up Disability Studies: A Report from the Edges of the Human Community
}

Tanya Titchkosky, Ph.D, Ontario Institute for Studies in Education of the University of Toronto

\section{Tanya.Titchkosky@utoronto.ca}

\begin{abstract}
This paper provides a report on first international Disability Studies Summer Institute hosted by the Ontario Institute for Studies in Education (OISE) of the University of Toronto, July, 2011. This report, reflective in character, narrates some ways that the Institute developed a critical understanding of "disability studies" that enabled attendees to re-encounter current conceptions of "problem" and of "people" and to re-think the relations between the two. This report discusses both keynote material and the experience of an evacuation because of a fire during the Institute. My aim is to reveal some of the ways disability is conceptualized, lived, and theorized as food for thought that can lead to further questions regarding the meaning of persons within the human community.
\end{abstract}

\section{Keywords}

Interpretation; Disability Studies Summer Institute; Recognition; Human; Becoming; Crisis; Evacuation 


\section{Firing Up Disability Studies: A Report from the Edges of the Human Community}

\section{Introduction}

The first international Disability Studies Summer Institute hosted by the Ontario Institute for Studies in Education (OISE) of the University of Toronto occurred during the week of July $18^{\text {th }}$, 2011. As it so happened, a summer heat wave accompanied us throughout our intense time together. Fifty emerging and established scholars from Canada, USA and UK attended the Institute, representing more than ten disciplines interested in exploring the significance of disability studies for both academic and everyday life. In what follows, I provide a report on the some of the understandings that arose through our time together.

The orienting aims for this gathering were rather simple: to address the conceptions of disability at work both in and out of disability studies so as to rethink them anew; to bring conceptions of race and disability in touch with one another so as to revisit their on-going separation; to do something other than celebrate disability studies arrival into the academy or to proclaim its marginal status as forgotten sister of those academic endeavours that preceded it. Basically, our aim was to make disability studies matter differently by reflecting on what it is we are already doing. Of course, there is already an intense and long history of self-critique generated by and for those within disability studies. Consider a few examples: Mike Oliver's (1999) characterization of disability studies research as reproducing the self-interest of the “parasite people;” Rod Michalko’s (2002: 143) examination of disability studies as it forgets it is imitating the conventions of belonging and thus forgets the necessity of continued critique of such conventions; Corbett O'Toole's (2004) demonstration of the sexist and racist inheritance of disability studies; Tom Shakespeare's (2004) noting of various critiques of the pursuit of 
disability rights as this leads to the wrong endeavor of patrolling the borders of disability studies; or Chris Bell's (2011: 4) demonstration of the whiteness of disability studies. Without dwelling on any one of these critiques, the Summer Institute grappled with the idea that some of the bestloved aspects of disability studies may, ironically, perpetuate the understanding of disability as a taken-for-granted problem over time and across various places around the globe.

What I intend in the pages of this report is to show some of the ways that we raised the issue of how disability studies might encounter its own conceptions of "problem" and of "people" so as to re-think the relations between the two. The following, then, is not a conventional academic paper but a reflective report. I provide an account of the Summer Institute, including an evacuation because of a fire, so as to show the ways disability is conceptualized, lived, and theorized as food for thought for those oriented to the continued need to question the nature of "problems" and "people."

\section{Key Notes in the Disability Studies Summer Institute}

This intense week involved three sessions a day where all present listened to a variety of people offer their work and with plenty of time, albeit never enough, for all to respond. I delivered the keynote on the first morning with "The Becoming Crisis of Disability Studies: Introductory Remarks," which is related to my new book The Question of Access: Disability, Space Meaning (Titchkosky, 2011).

The other keynotes were as follows: 
Nirmala Erevelles, The University of Alabama, "Disability as "Becoming" in (Post/Neo)

Colonial Context: Notes on the Political Economy of the Flesh" and related to her new book Disability and Difference in Global Contexts: Enabling a Transformative Body Politic (2011).

Dan Goodley, Manchester Metropolitan University, "What is Critical Disability Studies? And, Do We Need It?” and related to his new book, Disability Studies: An Interdisciplinary Introduction (2011).

Katherine McKittrick, Queens University, “On Blackness, Race, and the Struggle to be Human” and related to her book Demonic Grounds (2006).

Rod Michalko and Rinaldo Walcott, Ontario Institute for Studies in Education of the University of Toronto, "The Pleasure of the Humiliated Body," and related to Michalko's (2002) The Difference that Disability Makes and Walcott's (2000) Rude: Contemporary Black Canadian Cultural Criticism.

There was also one evening session open to the general public where the question "Why Disability Studies?" was addressed. With an audience of over 130 people, we put this question into conversation with audience members' interests in how differences in learning, in language, in accessibility requirements resulted in forms of disablement as well as a growing desire to question disability as a form of social devaluation particularly poignant in the lives of new immigrants. The formal presentations were short, the extended audience conversation was lively, and the event managed to generate a sense of the necessary inter-relation between wider community concerns and the DSSI concerns. 
Overall, the DS Summer Institute provided a means for scholars to question what disability studies is and what it needs to be in order for it to better address the on-going cultural production of disability as a "naturally excludable type" (Titchkosky 2007:149). It is, however, not easy to ask how to generate a crisis in our own understanding by researching the key concepts or critical analytic moves already at work in disability studies. It is also difficult to restlessly return to reflect on disability studies' current procedures and beliefs in order to face embodiment itself as a dynamic scene for social inquiry that is already related to, yet distanced from, other areas of cultural studies. Moreover, from the point of view of common sense, it would seem that problems of disability, and thus disability studies, are simply a little too obvious to fret about.

With the DS Summer Institute as background, and drawing upon aspects of my keynote, I turn now to a discussion of how disability is taken as problem that, regarded as obvious, may itself cause a variety of troubles. I will show how disability studies addresses this obvious character of disability-as-problem in ways that attempt to rupture the typical interpretive flow that moves from impairment, to disability, to disadvantage, to discrimination and danger for disabled people. I then provide an account of a fire evacuation during the final day of the Disability Studies Summer Institute as a way to further pursue a disability studies perspective that simultaneously questions what we are and are not doing with this perspective. I provide this account as a way to question what it is we react to when faced with those institutional social scenes that position disabled people precariously on the edges of what is imagined as the ordinary order of the human community. In other words, while my report does not take the shape of a conventional social science paper, it nonetheless provides a narrative structure within 
which we, reader and writer, can reflect on the movement of meaning as it is accomplished and enforced by the flow of daily academic life.

\section{The Obvious Sense of Disability as a Problem}

In the everyday academic culture, as Paul Abberley (1998) reminds us, it is ordinary to be interested in disability only as a problem and many disciplines work "on" this problem taken-forgranted as such. Let us turn to an obvious example of understanding disability as a problem and toward which disability studies holds some affinity. The World Report on Disability, recently released by the World Health Organization and the World Bank, certainly confirms the obviousness of disability understood as a problem. This new Report suggests, as has the UN in the past, that the "silent crisis" of the global state of disability is worse than first imagined:

\section{What do we know about disability?}

\section{Higher estimates of prevalence}

More than a billion people are estimated to live with some form of disability, or about $15 \%$ of the world's population (based on 2010 global population estimates). This is higher than previous World Health Organization estimates, which date from the 1970s and suggested around $10 \%$.

According to the World Health Survey around 785 million (15.6\%) persons 15 years and older live with a disability, while the Global Burden of Disease estimates a figure of around 975 million (19.4\%) persons. Of these, the World Health Survey estimates 
that 110 million people $(2.2 \%)$ have very significant difficulties in functioning, while the Global Burden of Disease estimates that 190 million (3.8\%) have "severe disability" - the equivalent of disability inferred for conditions such as quadriplegia, severe depression, or blindness. Only the Global Burden of Disease measures childhood disabilities (0-14 years), which is estimated to be 95 million (5.1\%) children, of whom 13 million (0.7\%) have "severe disability". (WHO, World Report on Disability, 2011: 7-8)

What do we know now about the problem of disability? According to the World Report, we know it to be located in certain bodies and to be more prevalent than previously thought. We know, too, that disability is a special some-thing; a thing that conditions the body; it is a measurable entity of rank-able and count-able severity; it is a billion conditions giving rise to difficulties for individuals; these difficulties may also be burdensome to others; disability is lack of function, disease, debilitating. The World Report tells us that we should know disability is difficulty ... it has struck a large number people who, if one reads on, are nonetheless regarded as though they are unexpected and unanticipated, as if disability was rare. We now know that disability is a 'they' who should be included, who should receive aid and assistance, but unfortunately do not. By mapping disability as individual difficulty, we are shown that there is much disability but little participation by disabled people in routine areas of daily life, such as learning, labour, leisure, and even love. We should also note that there is a strange overrepresentation of disability in some locales: in all forms of incarceration, in locales that have offices of social assistance or mental health or welfare regimes, in separate or special education classrooms, and anywhere there is poverty, war, or state brutality... these locales are very inclusive of disabled people. 
This is what we "know" now from this new report and it is this knowledge of the silent crisis of disability that the president of the WHO as well as the President of the World Bank "invite" us "to use this evidence in this report" to build an "inclusive world in which we are all able to live a life of health, comfort, and dignity" (World Report on Disability, 2011: 5). And yet, the world remains fairly quiet about its response to include the dysfunctional burden of the difficulty called individual impairment even when the world is responsible for its production through colonial exploitation; through war, technological advancements, and manufacturing; through environmental degradation as well as normal educational practices, etc.

Part of this lack of response is tied to the on-going social act of charting bodies from above, a kind of Archimedean point that (re)forges a notion of disability as a product of nature. Thus, disability is something that simply and obviously is and, just as obviously, what it is is a problem, and a difficult one at that. It comes to seem as though culture is far removed from the production of the entity called "person with a disability." This removal of culture results in the typical Western assumption that impairment is more or less caused by an individual's unfortunate fate (bad luck, bad genetics, injury, malnutrition, war, accident, wear and tear, job requirements, technological advancement, stress, trauma, difference). Such unfortunate fates, imagined as if natural, lead rather directly to the conclusion that disability "is" an "inability to do" in a "way considered normal" for a human being (WHO, 1980). Put in the language of the new Report (2011:7) the nature of impairment is such that it causes "difficulties functioning," as well as "activity limitations, and participation restrictions." A belief that these fates as well as their consequences are manufactured "as if" by nature provides a depiction of disability as somewhat unrelated to the culture within which it appears. Disability appears not as itself a 
cultural production but instead appears as an already given problem for cultures and towards which there are various responses (good and bad, enabling and disabling).

It is interesting that the Report remains curiously uninterested in the ways in which it conceives of disability as a problem in the first place. And so it comes to pass that the major solution to the problem is that the nation state and its people should learn to treat the problem that disability always already is in a "better" way - with more assistance and less discrimination. Thus, around the globe we have a rather cohesive research and administrative endeavour that teaches all involved, including disabled people, to believe that disability is already a problem; it is not culturally manufactured as such, but "we" should do "more" with what will forever be "less" which is the ruling definition of the condition of impairment. Strangely enough, it rarely comes to the fore for questioning that societies continue to make some people represent "the less-than of humanity" within a project that aims to build a more inclusive world.

Stranger still is that this dominant version of inclusion suggests that what we can know about disability is dependent on the body remaining a distinctly individual problem not configured as a collective one. Disability as a billion individualized nodes of difficulty, some representing the edges of humanity itself, becomes knowable as a burden for others. Mapped from above as though disability is simply a biological or functional calamity that has befallen a large number of an unfortunate few, it becomes millions of individual natural disasters to which others are being asked by the Report to respond and respond better.

This most ordinary and accepted, even normal and normalizing, conception of disability can still serve, though, as food for thought. 


\section{The Obvious Sense of Disability Studies}

From the perspective of disability studies, attending to this prevalent cultural representation of disability-as-problem begins to move us toward the need to develop a sense of a crisis, not in bodies, but in our ways of conceptualizing our bodies together in social space and over time. It was this understanding that grounded the organizing of the Disability Studies Summer Institute on the theme of a "becoming crisis" so as to address how disability is taken as problem in the first place. Disability studies itself represents the potential to offer a becoming crisis to current ways of understanding disability since it suggests ways to question the obviousness of "problem."

During the Institute, however, seeking this crisis in understanding came with a twist. Could we encounter, or even generate, a crisis in disability studies' own understandings of impairment, disability, and embodiment? Could we address what we already know in order to wonder about it? For example, does the obviousness of exclusion and discrimination faced by disabled people, especially through the primacy of medicalized definitions of our situation, have something new to say to us other than, once again, that disabled people experience exclusion and discrimination? If the exclusion of disabled people is understood as caused by failed social responses to different forms of embodiment (Oliver, 1996), and if it is common to narrate these exclusions as somewhat expected since disability is "naturally" too difficult, too severe, too burdensome, then are we not facing the very boundaries of the question of what it means to be human, or the edges of community sensibilities? In short, do we need to re-think what we are doing when offering critiques and explanations of exclusion, i.e., when we are doing disability studies? 
The Disability Studies Summer Institute can be characterized as an oriented entanglement with these sorts of questions. Such questioning helped us forge some new pathways to understanding disability as a dramatic and complex scene where critical interpretations regarding the cultural production of the meaning of persons can be encountered as part of embodied existence in everyday life. This cultural scene included our own conflicting orientations toward what disability studies is as well as how we imagine the social significance of bodies in social space over time. This prompted the Institute participants to ask about disability studies own institutionalized role in addressing disability as a "thing to be studied" that can end up reproducing so many lives as problem objects that are talk-about-able but nonetheless outside the play of mutual recognition or the interplay of co-constitution necessary to found human life.

But, we also imagined that disability is not best understood as a million natural disasters striking so many unfortunate few since it can be better addressed as a dramatic cultural scene where the question of what is human and what is natural are often asked. (This suggests that humanity can be uncovered through engaging with its denial.) Disability studies, if it is to examine the answers to such questions, or even raise them, needs to gear itself into a consideration of what counts as human in a culture that insists that the encounter with some bodies is an encounter of pure limit (not-quite-human) and as though limit can be split from possibility by those who count as all-too-human. To learn something new about the lives of disabled people without reflecting on the undergirding concepts of embodiment grounding this new knowledge production can reproduce the taken-for-granted sense of problem that provoked the research project in the first place. If, for example, disability is the problem of a lack of participation and is studied as such, what does disability studies need to do and be in order to do and be more than a confirmation of the current state of affairs? Moreover, among other arenas of 
critical studies of social exclusion (critical race studies, queer studies, gender studies) where disability still serves as a "naturally" exclude-able other, or serves as a taken-for-granted cut-off point of critical engagement, addressing embodiment may reinvigorate the desire to question any social practice that normalizes what counts as mainstream knowledge production. These ways of questioning suggest that what we know can become an occasion to put into crisis the question of how we know it.

Another twist: exploring the meaning of human and its resultant knowledge regimes are hardly possible if disability studies cannot question its own use of the categories of impairment, question its own identity politics and boundary building, and engage its celebrations of crip community. After all, the terms of our own engagement with discriminatory and able-ist culture also participate in that culture thus making some others into an unquestioned background against which the disabled figure arises as a problem. Yet another twist: recognizing the need for critical self-reflexive analysis, is not to invite complacency toward critical cultural research that refuses to avail itself of a disability studies perspective and instead continues to make "disability" a cutoff point for the nature/culture distinction. If we do not include a consideration of what critical work does with bodies, minds, senses and comportments that seem not to fit either in everyday life or in academic knowledge production, what remains of disability will always be that which is made to teeter on the edge of danger, degradation, and death.

The Disability Studies Summer Institute made clear that without an analysis of current cultural conceptions of embodiment, disability will pop up only as an impending emergency understood as its own self-contained crisis. War, storms, fire, economic downturns will continue to be occasions where societies position the disabled body precariously. Disability again and 
again triggers calls to "Flee," "Take cover," "Evacuate," "Tighten up your resources," or, "Get real, disability is beyond inclusion." Yet, how these manoeuvres are actually accomplished in the face of an almost universal desire to sustain a myth of normalcy as a collective Real with its liberal values of "inclusion," will continue to make some lives questionable and will continue to make human community precarious (Frazee, 2009). Thus we need to nurture a collective desire to re-think normalcy itself. By focusing on the cultural production of disability around the world as a crisis of exclusion as well as focusing on the cultural processes of peculiar inclusions of disability in the academy today, we can continue to uncover the ways normalcy remains a social phenomenon in need of further examination (Titchkosky and Michalko, 2009:1).

As a way to demonstrate the importance of re-thinking the "Real" of normalcy in key scenes of disablement and able-ism, I turn to an account of an evacuation that the DS Summer Institute participants underwent on our final day together. Of particular interest is not only what happened but, also, conflicting interpretations of what happened. An account of both the affront of the happening and how it can be interpreted will be pursued in what follows as a way to exemplify the "becoming crisis" offered by a disability studies perspective that orients to exposing conceptions of disability at work which help to sustain the normal and the ordinary.

\section{Evacuate!}

It is Saturday afternoon, July $23^{\text {rd }}$, 2011, the sixth day of the Disability Studies Summer Institute. Around 2:00 pm, we are having our final meeting in a fifth floor classroom of a twelve story downtown building of the University of Toronto. Organizing for this final meeting, I had expected only a small portion of the group of fifty to show up in order to plan for future projects. 
There were about 30 participants present, two of whom brought their young children. We were beginning to discuss projects that could arise from this intense week when our meeting, and as it turned out our Summer Institute, came to an abrupt end.

Through the open doors of the classroom we noticed firefighters proceeding down the hallway outside our classroom. They were calling out to each other, it sounded like they were looking for something on the large fifth floor outdoor balcony, or for keys to get out there. Two people from the Institute moved to where their children were playing outside the classroom. Soon, I also left the classroom and realized it was access to the balcony the firefighters were seeking. I began to look for the security phone since I knew Security would have the balcony door keys. I did not find the security phone. I did, however, find that the pay phone outside the accessible washroom was missing from the wall - a shaded paint stain indicating to me that a phone was once here. Despite no phone and just as firefighters started using the butt of an axe to break through the glass balcony door, a Security person showed up who was pressed into service to straightforwardly open the doors.

No fire alarm was sounding but more firefighters were arriving. The fifth floor was filled with the sound of firefighters' loud voices issuing directions to each other as well as the electronic clatter of voices over walkie-talkies; there had also been the thudding sound of their attempt to break through locked doors; and then, once the balcony was accessed, the smell of smoke flowing into the hallway near our classroom. While no one was speaking to our group, all these unusual sounds, sights, and smells, led me to believe that I should talk to someone in charge. 
One firefighter was standing near a red fire hose box near the balcony door. This hose box, like the doorway to the balcony, was in close proximity to our classroom. To this firefighter who was semi-stationary unraveling a fire hose, I said, "Should we evacuate?"

"Yes," he said.

I said that there were many people in our classroom who had mobility and other impairments. He said that the fire was out on the balcony. The firefighter did not appear too concerned, and I began to glean the impression that soon the fire would be under control, after all no alarm was sounding. So, stating more than asking, I said, “Oh, so we don't have to evacuate..."

"No. Evacuate," was the reply.

I repeated my prior comment and said that many people in our classroom have mobility impairments. This did not seem to make an impression on him as he did not respond. I got more specific, saying that there were wheelchair users, people with visual impairments. There were people who, if forced to use stairs, would face danger. I said very emphatically that we needed assistance and the firefighter said that he would send someone over. But the walky-talkies so frequently in use in the hallway, as well as the loud voices among the firefighters, remained silent on this issue. I continued... given that the fire is outside the building, could we use the elevators? "No," said the firefighter, since the elevators were under the control of the fire department. He continued with his work of unraveling the hose.

The smell of smoke was not as strong as the growing sense of threat that there would be no assistance. Repeating myself, I said that evacuating by stairs would be a problem. A 
different firefighter said, while moving out of the building on to the balcony, that he would send someone over. This never happened.

I returned to the elevator area, thinking that perhaps I simply missed locating the security phone. Still, there was no phone, but there was a blue poster that read:

\section{MOBILITY-IMPAIRED}

\section{FIRE PROCEDURES}

When stairs are not an option.

Know what to do. Be safe.

This poster had a little plastic slot that holds cards stamped with a big University of Toronto icon on one side and security phone numbers on the opposite side in tiny, eight font (perhaps smaller) lettering. When this card system was installed a few months earlier, there were complaints at faculty council about its inaccessible features. Now, I was simply sorry to find that the cards were missing. I did not have a pen on me and given my dyslexia, I did not attempt to memorize the security phone number posted outside the elevators.

Only a few minutes had passed. No fire alarm was sounding. No public announcement was made. Still, on my way back to the classroom, I heard a voice behind me say "Evacuate."

Back in the classroom, people had already begun to collect up their belongings. They told me that someone walking by the classroom had called into the classroom, "Take the stairs." I told the group that the firefighters do not seem too worried about the fire which was outside on the fifth floor balcony, but that they did want us to evacuate. 
Then -- it all happened fast and without guidance -- but this is what participants reported to me: People carried their colleagues down the stairs, one person slid down on their bum which could have exacerbated a health condition, while colleagues carried a wheelchair, others risked their own safety, e.g., sliding their foot down while grasping a rail in one hand a colleague in the other. Anxiety in the midst of so many unknowns abounded. For some, unfamiliar with the stairwells and reaching what they assumed was the exit door and finding it to be locked, a deep sense of dread ensued.

From my perspective, back in the fifth floor hallway, firefighters were still striding by the rest of us who continued to move toward the stairwell of the building to wait our turn down the stairs. The last four of us to evacuate represented the distinctive diversity of various sensory, emotional, physical, learning differences. Entering the stairwell, we were met by two people walking down the stairs and about to exit on to floor five. We told them of the fire and the evacuation. They hurriedly re-entered the stairwell and who they may have passed on the stairs below or what that passing may have looked like, I can only imagine.

We were ignored by all who had professional responsibility for security and safety that day. We also faced a series of environmental barriers such as missing phones and signage. Moreover, no one was willing to wait behind as per university protocol. Instead, the Disability Studies Summer Institute participants feared for each other's safety throughout the evacuation process and risked their own safety too, in favour of mutual support. This expectation for mutual support in times of trouble was not, however, shared by the authorities. Upon reaching the ground floor, many in our group encountered unhelpful campus police. The people who first left the building did not know if everyone made it down and tried to inform the firefighters of this 
fact via the campus police. Facing a lack of official recognition and response, while holding a basic but growing concern for one's colleagues, only added to a building sense of collective alarm. It is counter-intuitive that a lack of mutual recognition could be 'good' for anyone involved in emergency work but, somehow, this lack of response held together as a reasonable and universal response from authorities that day.

As a group, we eventually figured out that everyone was out of the building. As a group, we continued to wait outside during a heat wave, insisting that we needed to talk to the fire department about this dangerous evacuation experience, long after they may have believed the "crisis" had passed. No one wanted to leave without letting authorities know how dangerous the evacuation had been, and how unacceptable their response had been. We patiently waited, trying to engage police and security to discuss the events and learn more about both what had happened and what would happen next. Upon returning for the third time to the front door of the building, and as I saw fire-fighters heading toward the back exit door, I was told by campus police, to "Keep my ideas in my head," since this was now a fire investigation. I said that we, as a group, were part of what needed to be investigated. Facing only hostility, I returned to the group and continued to wait in the extreme afternoon heat. In the meantime, we were not asked any questions nor were any ones' health needs assessed by anyone officially involved in this evacuation. Some people had headaches, some were crying, some were sweating profusely, some were talking and others taking notes or pictures. From my perspective, it seemed we shared a troubled sense of a profound lack of recognition by officials regarding what we had undergone as well as a peculiar sense of camaraderie as a group toward whom such treatment is possible. 
Perhaps this is why everyone remained to express their thoughts both to campus police representatives and to the fire department's District Chief who came out to talk to us after the building was cleared for re-entry. Many spoke not only of a lack of assistance but also of a radical lack of understanding for the danger that was produced for us with this call to evacuate. There was, we insisted, a general failure to acknowledge us in our particularity, exacerbated by the failure to acknowledge what we had just gone through. Thus, our point, put most succinctly by one participant: "Not the fire, but instead the evacuation itself was the danger!" Emergency officials, processes, as well as the missing or impoverished emergency structures all worked together to fan this little fire into a blazing display of voided mutual recognition, including a lack of recognition for embodied differences.

Whatever else this account might be, it is the stuff of everyday life that is good to think with; that is, it was "borne of the aporia that engenders the interrogation of what it means to be human both individually and collectively" (Michalko, 2002:167). It is also a way to explore an array of circumstances which, combined, ironically enough to make a vivid illustration of one of our primary areas of interest at the Disability Studies Summer Institute, namely, the social constitution of the edges of humanity and its outsiders. Thus, I turn now to explicate some of this story from a disability studies perspective as a way to show the differing forms of "crisis" that are in play.

\section{Engaging the Evacuation}

It may seem obvious enough that a fire on an outside balcony that prompted no Official to sound the building's fire alarm represents only a little crisis poorly managed. However, from a 
disability studies perspective there are other ways to conceive of the crisis especially as this relates to understanding bodies in social space. For example, my account of the evacuation references bodies, specifically impairments, but to what end? Bodies described as impaired or different might be read as if they caused the danger of this evacuation. Recall too that disability is typically conceptualized and documented as a problem and this ubiquitous social act lends sense to the otherwise peculiar idea that embodied differences are a reasonable place to locate the problem of this evacuation. It is possible that by noting bodies I reproduce them as the problem and I do not draw to our attention to the unimaginative version of the "normal evacuee" that was being perpetuated by this scenario. But instead of reproducing a taken-for-granted sense of disability-as-problem, let us continue to examine it.

Starting from a most basic sense that disability is a social, not natural, phenomenon the danger of the evacuation is not located in our bodies. Neither emergency processes nor the bodies involved are signifiers of nature -- there is nothing "natural" to be found in this evacuation. Inadequate and as wrong as they were, the physical environment, the evacuation procedures, the forms of engagement by the firefighters, security, campus police, are social; they are social practices not predetermined by nature, not even by the nature of fires. The social practices and structures of evacuation interacted with this particular group of people transforming our differences or impairments into disabilities, and further transforming disabilities into dangers. To believe otherwise is simply to decontextualize the body. Thus, not bodies but rather their de-contextualization can now be understood as part of the crisis that caused the dangerous evacuation scenario. Understanding the evacuation in this way can put into crisis the taken-for-granted sense of disability-as-problem that the evacuation relied on and certainly reproduced. 
But what sort of problem was disability made to be? Given that none of the protocols, procedures, or environmental structures actually address the people who were asked to evacuate, or the actual people who work and learn in this University space every day, bodily differences were made into potentially deadly threats. Neither fires nor bodies need to be understood as "naturally" dangerous, but finding fires in contexts they are not expected, as well as making some bodies unexpected in some environments, makes for danger. The production of disabilityas-danger that day teeters on the edge of human rights violation as well as serious health and safety issues. Insult was added to injury when this did not appear to be immediately obvious to the officials involved who stood unconvinced that they had participated in the production of danger, thus repeating the degradation.

I can also report, however, on a further strange turn of events. A refusal to understand disability as a natural disaster waiting to happen, a refusal to take disability as a strange outsider that is impossible to include, and instead insisting on the necessity of human recognition between disability and non-disability, makes for a different sort of crisis in understanding that leads to immediate changes. "Job competency" and the "ordinary environment," for example, appear much differently when disability is not regarded as grounds for inaction and indifference. Suspending a belief in disability as always-already the problem, comes with a different set of consequences; it has led to framing the evacuation as catastrophically dangerous and not as a minor mis-hap; taking the perspective that disability belongs, has led to the Dean of OISE launching investigations and complaints and thereby changing environmental structures, protocols and personnel. When understood only as problem, however, impairment and differences end up framed by social processes that turn human embodiment against itself, displacing people from the space of mutual human recognition. 
But there is more to this crisis. Just as it turns out that the fire was not as dangerous as the evacuation was, so too the evacuation might not be as dangerous as are some of the other ways we now interpret it. For example, it is possible, even tempting, to say:

What a horrible thing to have happened - it could have been a lot worse. But perhaps the fire department and others did not know about disability, and thus they failed to do the right thing. Maybe now they will undergo disability awareness training. Then, things will be better. I am sure it won't happen again.

This seems to be a reasonable way interpret the evacuation but, still, a basic premise of a disability studies analysis is to consider what "reasonable responses" make of disability. The above expresses the idea that it is a lack of knowledge that is the problem and that disability awareness training might be the solution. Something about disability appears to be unknown. But what is it and what especially needs to come to be known?

People certainly need to know that stairs are not always an option. But this is known. The poster on every floor of the building that reads, "When stairs are not an option... be safe" announces, among other things, the common knowledge that stairs are not always a safe evacuation option. Perhaps the unknown is more precise, namely, that stairs are not an option for some people. But is this then an invitation to imagine yet another crisis located "in" certain bodies?

Reasoning that the production of danger occurred through a basic lack of disability knowledge suggests that it is not stairs as a mode of evacuation that needs to be re-thought but, instead, that there is something about bodies that needs to be learned. This potentially enforces an understanding of disability as "far out," since it is reasonable to assume that disability disrupts 
even the most common of lived experiences, namely, that every environment has limits and everybody moves ambiguously within these environmental limits. The inescapable reality of embodied existence as a context-dependent phenomenon is shared by every living person whether disabled or currently non-disabled. Put more basically, in evacuations sometimes nondisabled people cannot take the stairs thus revealing that the doing and the meaning of an evacuation is not dependant on bodies alone. To ignore or forget non-disability's tie to embodied ambiguity situated in the context of environmental limits and to make disability's tie to this ambiguity so "far out" that mutual recognition disappears is to erect a (mythical) dividing line. Disability may even be made to represent a line of no return. Moreover, the assumption that professionals need more awareness of disability as a really-far-out-alien-location-of-disruptiveambiguity is unlikely to change the social processes at play that throw disability on to one side of the line between mutual recognition of the human community and its opposite. Still, thrown to one side, it then becomes reasonable to conceive of disability-knowledge itself as a barrier to other people competently accomplishing their jobs.

\section{Lessons Learned}

Interpretive responses to the evacuation attest to at least two lessons. There are social processes in play that serve to transform difference or impairment into disability-as-danger. There are also social processes at play that transform seemingly reasonable responses to embodied differences into a place for questioning and inquiry. Sometimes this latter form of transformation is called "disability studies" and as a transformer of normal reasoning into a space of questions it plays a role in undoing the normalization of injustice and human degradation. It is this perspective that 
animates my need to regard dangerous events not only as in need of documentation but also in need of analysis. The sense we make of difficult disability events can be examined for how it plays a part in the production of the crises that make some people count as less than human. It is not simply that some bodies do not matter. It is instead that disability is made to matter as if it is decontextualized from the human community that both causes the crisis that disability is made to be and itself needs to be put in crisis through critical inquiry.

A failure to consider the conceptions of disability that already inform our engagement with our bodies, minds, senses, comportments, is to risk... no, is to enforce the status quo. This solidifies the normalization of human diminishment. Disability as currently conceived and governed - almost always as problem and never as promise (Titchkosky, 2011b) - normalizes the notion that there are some humans too questionable to live with, or to imagine including, hanging out with, or building into collective everyday realities. Disability studies invites a consideration of the versions of (non)human that are difficult to include into our physical and imaginative structures as anything but crisis, burdensome, or dangerous in order to reconsider cut-off points for participation, worth. Thus we also perhaps revisit conceptions of the human itself. We need not only celebrate the arrival of disability studies into the academic scene, or rehearse its internal critiques, but also regard our work as an occasion to focus on the margins of the question of the human. 


\section{References}

Abberley, Paul. (1998). 'The Spectre at the Feast: Disabled People and Social Theory' T. Shakespeare (ed.) The Disability Reader: Social Science Perspectives. London: Cassell Academic. pp. $79-93$.

Bell, Christopher M. (Ed). (2011). "Introduction: Doing Representational Detective Work," Blackness and Disability Studies: Critical Examinations and Cultural Interventions. Switzerland: LIT Verlag Press. pp. 1-8

Erevelles, Nirmala. (2011). Disability and Difference in Global Contexts: Enabling a Transformative Body Politic. UK: Palgrave MacMillian.

Frazee, Catherine (2009, Nov. 5). "Disability In A Dangerous Time: Public Lecture By Catherine Frazee,” Ontario Institute for Studies In Education, New College Disability Studies Speaker Series 2009, University of Toronto.

Goodley, Dan. (2011). Disability Studies: An Interdisciplinary Introduction. Los Angeles: Sage.

McKittrick, Katherine. (2006). Demonic Grounds: Black Women and the Cartographies of Struggle. Minnesota: Minnesota University Press.

Michalko, Rod. (2002). The Difference that Disability Makes. Temple: Temple University Press. 
Oliver, Michael. (1999). "Final Accounts and the Parasite People," in Disability Discourse.

Eds., Mairian Corker and Sally French. Buckingham: Open University Press. pp. 18391.

Oliver, Michael. (1996). The Politics of Disablement: A Sociological Approach. New York: St. Martin's Press.

O’Toole, Corbett Joan. (2004). “The Sexist Inheritance of the Disability Movement,” in Gendering Disability. Eds. Bonnie G. Smith and Beth Hutchison. New Jersey: Rutgers University Press. pp. 294-300.

Shakespeare, Tom. (2006). Disability Rights and Wrongs. New York: Routledge.

Titchkosky, Tanya. (2011a). The Question of Access: Disability, Space, Meaning. Toronto: University of Toronto Press.

---. (2011b.) "The Promise of Disability," in editors, Carol Rolheiser, Mark Evans and Mira Gambhir. Inquiry into Practice: Reaching Every Student Through Inclusive Curriculum Practices, OISE Press. 16-17.

---. (2007). Reading and Writing Disability Differently. Toronto: University of Toronto Press.

Titchkosky, Tanya and Rod Michalko. (2009). Rethinking Normalcy: A Disability Studies 
Reader. Toronto: Canadian Scholars Press.

World Health Organization [WHO]. (1980). International Classification of Impairments, Disabilities and Handicaps: A Manual of Classification of Relating to the Consequences of Disease. Geneva, Switzerland: World Health Organization of the $29^{\text {th }}$ World Health Assembly.

World Health Organization. (2011) World Report of Disability. Geneva, Switzerland: WHO Press http://www.who.int/disabilities/world_report/2011/report/en/index.html

Walcott, Rinaldo (2000). Rude: Contemporary Black Canadian Cultural Criticism. Toronto: Insomniac Press.

\footnotetext{
i The Disability Studies Summer Institute was funded by the Dean of OISE, Julia O'Sullivan, and supported by Rinaldo Walcott the Chair of Sociology and Equity Studies in Education at OISE, as well as by my SSHRC grant, "The Cultural Production of Disability as an Excludable Type in University Life," held with Rod Michalko. The full schedule of presentations, other related texts as well as some presentations are archived at Manchester Metropolitan University http://disabilitystudiessummerinstitute.posterous.com/
} 